\title{
APOSENTADORIA POR IDADE RURAL: RELAÇÃO JURÍDICA PREVIDENCIÁRIA OU ASSISTENCIAL? UMA REFLEXÃO NECESSÁRIA.
}

\author{
Marco Arlindo Tavares ${ }^{1}$
}

\section{Resumo:}

Este trabalho traz necessária reflexão sobre a aposentadoria por idade ao trabalhador rural que é prevista como seguro social. Fundamentado no marco teórico de Wladmir Matinez, o resultado da pesquisa perpassa pela historicidade do instituto e, por método dedutivo, sugere alongar o olhar sobre o benefício que é pago por orçamento do regime geral da previdência social. O benefício hoje é visto e analisado de forma subjetiva em decisões judiciais e é visto como assistencial, outro núcleo da seguridade, o que pode causar desequilíbrio e risco ao sistema geral.

Palavras-chaves: relação jurídica, aposentadoria, rural, previdenciário, assistencial

\section{RETIREMENT FOR RURAL WORKERS: SOCIAL SECURITY OR ASSISTANCE RELATIONSHIP? A NECESSARY REFLECTION.}

\begin{abstract}
:
This work makes necessary reflection on the retirement to the rural worker that is foreseen as social insurance. Founded on the theoretical framework in Wladmir Matinez, the research goes through the historicity of the social insurece and, by means of a deductive method, it suggests extending the look on the benefit that is paid by the budget of the general social security system. But the retirement is seen and analyzed subjectively in judicial decisions that see it as assistance, another core of security, which can cause imbalance and risk to the general system.
\end{abstract}

Keys-words: legal relationship, retirement, rural, social security, assistance

\section{INTRODUÇÃO.}

O direito previdenciário, como disciplina própria que promove a Seguridade Social, está inserido no subsistema jurídico que visa regular a relação jurídica entre o interessado e o seguro social, a conceituação, os princípios e as diretrizes que são essenciais para a manutenção e o equilíbrio do sistema. No que tange à relação jurídica previdenciária do cidadão rural e à aposentadoria por idade há conflitos que precisam de reflexões, sob pena de colocar em risco a estrutura do sistema.

\footnotetext{
${ }^{1}$ mestrando no Programa de Pós Graduação em Direito da Universidade FUMEC. Procurador Federal, membro da Advocacia-Geral da União. Lattes: http://lattes.cnpq.br/4091616670251217. e-mail: marcoatavares@gmail.com.
} 
Dada a complexa estrutura social que envolve o trabalhador rural como uma das classes minoritárias da sociedade brasileira, não é difícil entender que possa haver disparidade em relação à forma de olhar a natureza jurídica do benefício destinado a esses cidadãos, em especial aquele previsto na norma do art. 143, da Lei n.8.213 de 1991 (BRASIL, 1991).

A Administração Pública conceitua como previdenciária a relação jurídica do trabalhador rural com o sistema previdenciário e vê a aposentadoria por idade como um seguro a ser entregue somente quando comprovado ter ocorrido o evento idade avançada e o trabalho rural. O Poder Judiciário o tem, na maioria das vezes, como uma relação assistencial (TAVARES, 2020, p.189).

A divergência conceitual quanto à natureza jurídica do benefício é fator que, além de desencadear a perda de parte da titularidade da outorga de entrega do direito da aposentação rural, pode colocar em risco o sistema previdenciário.

Visando trazer elementos que possibilitem uma reflexão, de forma a ampliar o debate sobre o tema-problema, este trabalho foi desenvolvido tendo a doutrina de Wladimir Novais Martinez como referencial teórico.

O resultado da pesquisa apresenta a origem da proteção social feita aos trabalhadores nas conceituações bismarckiana e beveridgiana, e aponta a estratégia brasileira para fazer a proteção dos trabalhos rurais em virtude da idade, que se caracteriza como política pública. Mas esse instituto, a aposentadoria, parece se perder na objetividade das características do seguro, o que permitiu criar desarmonia entre a Administração Pública e o Poder Judiciário quanto o entendimento da sua natureza.

A pesquisa bibliográfica fundamenta os apontamentos, de forma dedutiva, dos conceitos, princípios e da racionalidade crítica quanto ao direito previdenciário que apontam o benefício como parte do regime geral de previdência social. São apresentados os resultados obtidos por pesquisa documental, análises aleatórias de decisões de cada um dos Tribunais Regionais Federais brasileiros, que induzem um pensamento jurisprudencial hermético de ser o benefício de natureza assistencial.

Assim, finalmente, são efetuadas as considerações finais no sentido da necessidade de uma definição completa quanto a natureza do benefício previsto no subsistema do direito 
previdenciário para os trabalhadores do campo, sob pena de colocar em risco o orçamento da seguridade social.

\section{O REGIME GERAL DA PREVIDENCIA SOCIAL NO BRASIL.}

Os elementos básicos de manutenção da vida social, que vão desde um mínimo financeiro para subsistência até a garantia de uma velhice digna, tiveram seus ideais reivindicados no século XVIII, sendo expressados em instrumentos legais somente a partir do século XIX (VALADARES e GALIZA, 2016, NT).

Em se tratando da experiência brasileira de construção dos direitos sociais, sobretudo de uma sistemática de política social, pode-se afirmar que o reconhecimento da obrigação social do Estado e a garantia do direito de regular o exercício de profissões principia com a Constituição da República Federativa do Brasil de 1934 (VALADARES e GALIZA, 2016, NT).

Anteriormente, “o Estado brasileiro se mantinha inflexível quanto à intervenção do poder público nos processos acumulativos" (BARBOSA, 2005, p. 05). Antes da Lei Eloy Chaves - 1923 - que criou as Caixas de Aposentadorias e Pensões, considerada marco inicial da política social no Brasil, apenas foi obtida a regulamentação dos acidentes de trabalho (BARBOSA, 2005, P. 05).

Doutrinadores que se debruçam em estudos sobre direitos sociais, como Barbosa (2005) e Vianna (1999), argumentam que a partir do período de governo de Getúlio Vargas os direitos sociais estiveram geralmente atrelados à condição de pertencimento à determinada categoria de trabalhador, com a devida carteira de trabalho assinada, o que garantiria ao cidadão o acesso a políticas sociais específicas. A partir dessa premissa, tem-se que o trabalhador é reconhecido como cidadão pelo seu vínculo às corporações profissionais.

No que tange aos trabalhadores rurais brasileiros, o Estatuto do Trabalhador Rural, promulgado em 1963, previu a criação da previdência social para esses profissionais, mas sua regulamentação se efetivou em 1971, com a instituição do Fundo de Assistência ao Trabalhador Rural (Funrural).

Após longo período de restrição dos direitos, em especial os sociais, pela administração pública militar, os direitos sociais foram reestabelecidos com previsão 
constitucional, com o novo estado brasileiro constituído em 1988, a que chamamos democrático.

Jane Lucia Wilhelm Berwanger (2008, P. 124) explica que a inserção do segurado especial na Constituição Federal se dá por diversos motivos, dentre eles o reconhecimento profissional dessa classe; a não discriminação entre trabalhadores rurais e trabalhadores urbanos; ênfase no caráter previdenciário e não mais assistencial; e a responsabilidade de efetivar os direitos sociais ao campo.

Como ordem social, também foram organizadas em normas constitucionais as possíveis prevenções em face de contingências humanas, como a idade avançada, doença que impeça a continuidade de produção e renda, ocorrência de óbito, proteção à maternidade e também proteção ao trabalhador em situação de desemprego involuntário e aos filhos de trabalhador de baixa renda recluso sob a custódia do Estado.

Porém, como a cobertura das contingências previstas tem custos financeiros, a própria Constituição da República Federativa do Brasil de 1988 (CRFB/88) previu também a forma de custeio das previdências. O financiamento se dá de forma contributiva pelos trabalhadores e é parcialmente rateado solidariamente entre todos os demais participantes da sociedade, em um Regime Geral de Previdência Social.

\section{A RELAÇÃO JURÍDICA PREVIDENCIÁRIA COMO SEGURO SOCIAL NO MUNDO.}

A Constituição da República de 1988, ao capitular a seguridade social, perseguiu a manutenção de vida digna e reservou seção específica para garantir prevenção em face de fatos da vida, por previdência social, organizando-a em regime geral de caráter contributivo e de filiação obrigatória a todos trabalhadores.

Apesar da compulsoriedade que abrange o trabalhador, estudiosos jurídicos como Alencar (2018) e Martinez (2017) afirmam que a previsão constitucional para se fazer previdência social se dá por instituto de natureza de seguro social. E essa afirmação tem fundamento.

As primeiras formas de seguro, como o seguro marítimo, reivindicação dos comerciantes italianos, surgiram ainda no século XII, mas não tinham suas bases técnicas e jurídicas do seguro contratual (VENTURI, 1994, p. 77) 
O desenvolvimento do instituto do seguro fez surgir novas formas de seguro como o de vida, contra invalidez, de danos, em face de doenças e acidentes, etc. De natureza facultativa, eles decorriam de contratos, dependendo da manifestação da vontade do interessado, e tinham no Direito Civil as suas bases.

Surgiram então, as empresas seguradoras com fins lucrativos e com administração fundamentada em critérios econômico-financeiros. O prêmio era precificado em valor que a maior parte da população não podia cobrir, tornando a proteção securitária privilégio de uma minoria. Então, tornou-se necessário criar um seguro de natureza obrigatória que protegesse os economicamente mais frágeis, aos quais o Estado deveria prestar assistência.

Afirmando-se a necessidade de criar um seguro obrigatório, Santos é certeira ao citar Augusto Venturi que ensina (em tradução livre): ${ }^{2}$

\footnotetext{
${ }^{2}$ Ibid., p. 99: "27. Frente a las exigencias que las condiciones objetivas y la ya difundida sensibi- lidad ante las 'injusticias' sociales, cada vez más evidentes en la vida moderna, las soluciones de la beneficencia, de la asistencia pública, del socorro mutuo, del seguro voluntario, incluso sumando todas sus aportaciones al auxilio de las victimas de las visicitudes de la vida, resultaban absoluta- mente inadecuadas. Era necesario dar um nuevo paso hacia adelante y este se dio con el reconoci- miento de uma doble necesidade: de un lado, rendir obligatorias, para todos los que pertenencían a importantes categorias de trabajadores, forma de seguro frente a los riesgos que se encuentram sujetos - cuestión que, necesariamente, debía ser competencia del Estado -; de outro lado, ayudar a los trabajadores a soportar el coste de estos seguros - y, también aqui, el Estado debía adoptar alguna medida, llamando a contribuir la categoria de los empleadores".
} 


\begin{abstract}
Diante das exigências das condições objetivas e da já difundida sensibilidade ante as 'injustiças' sociais, cada vez mais presentes na vida moderna, as soluções da beneficência, da assistência pública, do socorro mútuo, do seguro voluntário, inclusive somando todas as suas contribuições ao auxílio das vítimas das vicissitudes da vida, resultavam absolutamente inadequadas. Era necessário dar um novo passo adiante e este se deu com o reconhecimento de uma dupla necessidade: de um lado, tornar obrigatórias, para todos os que pertenciam a importantes categorias de trabalhadores, formas de seguro frente aos principais riscos a que se encontram sujeitos - questão que, necessariamente, devia ser competência do Estado - ; de outro lado, ajudar os trabalhadores a suportar o custo desses seguros - e, também aqui, o Estado devia adotar alguma medida, chamando a contribuir a categoria dos empregadores.” (SANTOS 2020, p. 03)
\end{abstract}

A doutrina de Ibraim (2018) e Santos (2020) atribui que o seguro social, com característica de seguridade social, nasceu na Prússia em 1883, com a Lei do Seguro Doença, que criou o Seguro de Enfermidade, proposta de Otto Von Bismarck como programa social.

A partir de Bismarck, a obrigatoriedade da participação de todos os trabalhadores, e não mais restrito aos trabalhadores da indústria, bem como a universalidade da cobertura de riscos como doença, acidente, invalidez, velhice, desemprego, orfandade e viuvez, deu força ao seguro a alcançar o status de previdência social.

Com a obrigação de participação de todos os trabalhadores, o seguro social passou a conferir direito subjetivo. Todos contribuíam, mas esperavam uma contraprestação quando necessária.

Com o estado liberal, era preciso criar mecanismos que permitissem a redução das desigualdades sociais. O Estado passou a organizar e administrar o seguro social. O custeio era diversificado, feito pelos empregadores, os empregados e o próprio Estado, não cabendo firmar natureza civilista dos contratos anteriores de seguro.

Pelo seguro social, como instrumento de redistribuição de renda, viabilizou-se o consumo e deu-se contornos jurídicos à solidariedade, tornando-o elemento fundamental no conceito de proteção social que, cada vez mais, foi se afastando dos elementos conceituais do seguro civilista. Mas a participação, como dito, estava condicionada à contribuição do interessado (SCHWARZER, 2001, p. 124). 
O seguro social, na concepção bismarckiana, estendeu-se pela Europa até meados do século XX, mas o sistema não resistiu à Primeira Guerra, quando se tornou necessário fazer a cobertura para um grande número de órfãos, de viúvas e de feridos que resultaram dos combates, somando-se a esses fatos ao aumento exponencial da inflação à época, os quais foram sentidos principalmente na Alemanha e na Áustria.

Diante da situação fática, após Tratado de Versalhes em 1919, surgiram os compromissos para um novo regime universal de justiça social, com a fundação do Bureau Internacional Du Travail (BIT) - Repartição Internacional do Trabalho (DEPP, 2009, p 17). Pelas Conferências Internacionais do Trabalho do BIT, passou-se ao desenvolvimento da previdência social e da sua implantação em todas as nações que naquele momento podia fazêlo.

Somente na Terceira Conferência de 1921 do BIT recomendou-se a extensão do seguro social aos trabalhadores do campo.

O BIT teve papel importante na expansão da previdência social pelo mundo (GEPP, 2009, 17). O seguro social é espécie do gênero seguro que, embora com características próprias, ainda tinha muito do seguro privado, o que o permitia também selecionar os riscos que seriam cobertos pelo orçamento a ele destinado. O risco de incerteza de ocorrência do sinistro e a formação de um fundo comum, administrado de forma a garantir econômica e financeiramente o pagamento das indenizações, são características do seguro social e do seguro privado. Porém, a universalização e a natureza obrigatória do seguro social o diferenciam do seguro privado, que tem natureza eminentemente facultativa.

A expressão seguridade social foi introduzida pela Social Security act que, em razão da crise econômica de 1929, foi promulgado pelos Estados Unidos da América (EUA) em 1935. Ao comentar sobre a Social Security act dos EUA, Paul Durant ressalta que (em tradução livre):

A Lei de Seguridade Social se caracterizou por três eixos fundamentais: a superação das particularidades dos diversos Estados-membros; a organização de um sistema bastante amplo de indenização de riscos sociais; e a decisão de impedir que novas instituições alterem o espírito de iniciativas do povo americano (DURANT, 1991, 9. $152)$. 
A legislação securitária alcançou seu ponto máximo como advento do Convenção $\mathrm{n}^{\circ}$ 102, aprovada pela XXXXV Conferência do Trabalho do BIT que instituiu a denominada norma mínima em matéria de seguridade social.

Já a partir de 1941 na Inglaterra, um trabalho encabeçado por Willian Beveridge demarcou e impulsionou nova regulamentação legal da seguridade social (SCHWARZER, 2001, p 120).

Com o fim da segunda guerra, percebendo que os cidadãos se encontravam debilitados, o governo britânico nomeou o economista inglês conhecido como Beveridge para presidir uma comissão encarregada de elaborar um relatório sobre a seguridade social da Inglaterra. As propostas contidas neste relatório deram início aos modernos sistemas de seguridade social consubstanciados nos princípios da "proteção para todos" (SCHWARZER, 2001, p 120).

O trabalho de Beveridge tinha como escopo a proteção daqueles que até então eram excluídos dos antigos seguros sociais, (universalidade subjetiva) e também estender ao maior número possível de risco do sistema da seguridade social (universalidade objetiva).

Além da universalidade objetiva e subjetiva, são características da seguridade social, proposta por Beveridge, a unidade de gestão, determinando ao Estado a obrigação de prover os meios de vida através da criação de serviços públicos em lugar do serviços privados; igualdade de proteção, que consiste na atribuição de benefícios iguais para idêntica situação de necessidade; e a solidariedade financeira, consagrando que toda a sociedade deve cooperar com o financiamento da seguridade.

Em 1948, a Declaração Universal dos Direito Humanos (Assembleia Geral da ONU, 1948) proclama em seus artigos 22, 25 e 28 como direito humano universal o direito à seguridade social.

\section{O TRABALHADOR RURAL BRASILEIRO COMO SEGURADO DO REGIME DE PREVIDÊNCIA SOCIAL.}

O sistema previdenciário brasileiro, a partir de 1988 garantido constitucionalmente, tem característica bismarckiana, que estipula como regra de acesso a contribuição prévia e mensal ao seguro social. 
Qualquer cidadão brasileiro que queira se aposentar por idade por exemplo, deve antes contribuir por cento e oitenta meses consecutivos, período chamado de carência, além de ter uma idade mínima de sessenta dois anos de idade caso seja mulher e sessenta e cinco anos caso seja homem (BRASIL, 1991).

Reconhecendo a hipossuficiência cultural, social e econômica dos trabalhadores rurais, ante necessária universalidade de cobertura, o Estado brasileiro provisionou através de normas jurídicas, assegurá-los com cobertura de eventos sociais com benesses, exigindo o cumprimento dos requisitos de forma diferenciada aos que normalmente são aplicados aos demais trabalhadores brasileiros em atividades urbanas.

Atenta à necessária política pública ao trabalhador rural Jane Berwanger afirmou que "por certo que a Constituição Federal deve ser o norte de toda legislação, inclusive a previdenciária e, assim, os trabalhadores rurais foram incluídos como segurados do sistema de Previdência Social, e não são mais beneficiários de programas assistenciais" (BERWANGER, 2008)

Rômulo Soares Barbosa (2006) adverte que “com a Constituição de 1988 os agricultores passaram a ser incluídos como segurados especiais no sistema previdenciário dos trabalhadores rurais" (BARBOSA 2006, p. 02). De fato, pode-se notar a partir de estudos realizados pelo Instituto de Pesquisa Econômica Aplicada (IPEA) que o processo denominado Universalização da Previdência Rural ganhou notoriedade, quando se toma por base a análise sobre os seus efeitos socioeconômicos, tendo como ponto central a dimensão de combate à pobreza.

Para Barbosa (2006, p. 16), “o combate à pobreza tem sido destacado como o principal efeito do processo de universalização da Previdência Social Rural, na medida em que são incorporados ao sistema previdenciário segmentos sociais empobrecidos”.

Para os alcances dos efeitos das benesses previdenciárias, o legislador brasileiro entendeu necessário afirmar quem são os trabalhadores considerados rurais a serem contemplados.

Por meio de lei n. 8.213 de 1991 (BRASIL, 1991), especificamente pela norma do art. 11, VII, cunhou-se os diferentes profissionais que integrariam a categoria de segurados especiais. Mas a própria Lei deixou campo vasto para, por hermenêutica, estender a categoria a outros profissionais ali não mencionados. 
Diz a norma que são segurados obrigatórios da Previdência Social, como segurado especial, o produtor, o parceiro, o meeiro e o arrendatário rurais, o garimpeiro, o pescador artesanal e o assemelhado que exerçam suas atividades, individualmente ou em regime de economia familiar, ainda que com o auxílio eventual de terceiros, bem como seus respectivos cônjuges ou companheiros e filhos maiores de quatorze anos ou a eles equiparados, desde que trabalhem com o grupo familiar respectivo.

Estendendo-se, a norma ainda diz que se entende como regime de economia familiar a atividade em que o trabalho dos membros da família é indispensável à própria subsistência e é exercido em condições de mútua dependência e colaboração, sem a utilização de empregados.

Há previsão legal para que os segurados especiais façam a contribuição prévia com aplicação de alíquota mínima sobre a produção rural que se fizer anualmente, cabendo a Administração manter base de dados de cadastro e informações dos produtores rurais por termo de autodeclaração (art. 38-B, Lei 8.213 de 1991).

Diferentemente do segurado especial, o empregado rural está regulado pelo art. 11, I, da Lei n. 8.213 de 1991 (BRASIL, 1991) c.c. art. 14-A, da Lei n. 5.883 de 1973 (BRASIL, 1973) - sendo aquele que possui contrato de trabalho empregatício com empresas ou pessoas físicas em atividade do campo. Já o trabalhador diarista, que não possui vínculo empregatício, trabalha em regime de pagamento de diárias para uns e outros contraentes dos serviços. Esse último, alcunhado boia-fria, por sua vez, estaria regulamentado pela norma do art. $11, \mathrm{~V}, \mathrm{~g}$, da Lei 8.213 de 1991 (BRASIL, 1991), denominado contribuinte individual.

A generalidade trazida por assemelhados e a própria qualificação de regime de economia familiar chamaram os especialistas ao debate quanto à abrangência ou não à categoria de segurado especial de profissionais rurais que trabalham, por exemplo, sob regime de diária para diversos fazendeiros. Numa visão legalista, esses últimos profissionais deveriam contribuir mensalmente, já que não são abrangidos pela qualificação de segurado especial. Mas pacificou-se jurisprudência para afirmar que os diaristas rurais, chamados boias-frias, também são considerados segurados especiais, e não segurados facultativos, para os fins das benesses previdenciárias, visto não haver equilíbrio em se fazer diferenciação para categorias que se encontram em condições de similitude (BRASIL, 2018). 


\section{INGERÊNCIA NA ADMINISTRAÇÃO DA APOSENTADORIA AO TRABALHADOR RURAL E SUAS CONSEQUÊNCIAS.}

As políticas da seguridade social sempre foram verdadeiros bálsamos no estado brasileiro. No que tange às pessoas do campo, Barbosa (2006) considera que "os efeitos do benefício previdenciário para a renda das famílias rurais vêm contribuindo para um processo de superação da "linha de pobreza" (BARBOSA, 2006, p. 23). No caso do Nordeste, onde o índice de pobreza rural é relativamente maior do que nas regiões do centro-sul, pode-se observar que ocorre um fenômeno de redução de $51,5 \%$ para $38,1 \%$ do volume de domicílios enquadrados como pobres (IPEA, 2000, p. 19). A injeção de recursos via concessão de benefícios previdenciários aos idoso(a)s rurais tem sido um fator de impactos no conjunto de recursos manejados pelas famílias rurais, com efeitos expressivos para o combate à pobreza.

No entanto, há que se fazer uma reflexão quanto a capacidade da Administração Pública em gerir a política pública previdenciária ao homem do campo, em especial a aposentadoria por idade rural.

A aposentadoria por idade do Regime Geral da Previdência Social, que em regra está tratada no art. 48 da Lei n. 8.213, de 1991 (BRASIL, 1991), e tem sua forma especializada aos trabalhadores rurais nas normas dos $\S \S 1^{\circ}, 2^{\circ}$ e $3^{\circ}$ do mesmo artigo e no artigo 143, também da Lei $\mathrm{n}^{\circ} 8.213$ de 1991 (BRASIL, 1991), com as alterações introduzidas, respectivamente, pelas Leis n. 9.063 e n. 9.032, ambas de 1995 (BRASIL, 1995).

De acordo com essas normas, o trabalhador rural tem o requisito idade diminuído em cinco anos e a substituição do número de carência pela comprovação do trabalho efetivo campesino pelo mesmo período. No Brasil, basta o homem comprovar que possui sessenta anos, e a mulher cinquenta e cinco anos, e que tenham trabalhado por mais de cento e oitenta meses no campo para que se afirme a relação jurídica previdenciária e, consequentemente, o direito à aposentação por idade.

Por norma legal, substituiu-se o período de carência por meses de efetivo trabalho em campo rural para esses profissionais. Nesse caso, pode-se dizer que o sistema que era absolutamente bismarckiano tomou ares do sistema beveridgiano.

No modelo beveridgiano não se exige contribuição individual anterior de todos os segurados para a obtenção de um benefício, aferindo-se o direito à prestação por alguma característica definidora de cidadania. 
Ainda que beveridgiano, o tempo de serviço só será computado, reconhecido, para fins previdenciários, apenas quando estiver alicerçado em razoável início de prova material $\left(\S 3^{\circ}\right.$, do art. 55, da Lei 8.213 de 1991) que possa incendiar a veracidade do trabalho no campo.

Nesse sentido, foi editado o enunciado $\mathrm{n}^{\circ}$ 149, da Súmula do Superior Tribunal de Justiça (STJ): “A prova exclusivamente testemunhal não basta à comprovação de atividade rurícola, para efeito de obtenção de benefício previdenciário."

Não sendo aceita a comprovação exclusivamente testemunhal, a norma do artigo 106 da Lei n. 8.213 de 1991 (BRASIL, 1991), alterada pela Lei n. 11.718 de 2008 (BRASIL, 2008), enumera rol de documentos que devem ser utilizados como início de prova material para se fazer a comprovação do exercício da atividade. Visando a legalidade, a Administração Pública engessou, de forma burocrática, o pedido do benefício pelo trabalhador rural, apontando e enumerando os documentos contemporâneos a serem apresentados.

Com a mesma mão que oferece benesses, por reconhecer a hipossuficiência cultural do trabalhador rural, a Administração Pública exige que esses hipossuficientes forneçam documentos específicos, enumerados e contemporâneos, que guardem relação com suas atividades profissionais.

Como trabalhador de primeira-mão, de vida modesta e muitas vezes não alfabetizado, não é comum a ele produzir documentos oficiais. E quando o faz, normalmente é feito apenas em nome daquele que é responsável pelo grupo familiar

Com o fim de efetivar uma das finalidades previstas na CRFB/88 para a previdência social, destinadas a assegurar os direitos relativos à previdência, caberia a Autarquia Previdenciária, a quem a Lei outorgou a administração dos benefícios previdenciários, providenciar instrumentos que pudessem reproduzir a verificação dos fatos, como diligência in loco, maior capacitação e discricionariedade dos servidores para análise de materiais a informar a vida rural do interessado, sem se prender às exigências enumeradas em normas jurídicas.

Ocorre que a exigência condicional do início de prova material feita na forma da Administração tem inviabilizado a utilização da política pública, tornando-se necessário se socorrer da tutela jurisdicional para a devida correção. 
De acordo com o IPEA (2018, p. 21), percebe-se um crescimento, em taxas significativas, entre 2008 e 2014, de $30 \%$ para pedido de tutela jurisdicional de aposentadoria por idade rural, que chega a cada ano nas seções judiciárias de primeira instância pertencentes ao Tribunal Regional Federal da $1^{\circ}$ Região. Taxas semelhantes ocorrem nas seções judiciárias dos Tribunais Regionais Federais das demais regiões.

Ainda, segundo IPEA (2018, p. 25), não bastasse o número crescente de demandas judiciais a cada ano, também é cada vez maior a positividade das tutelas jurisdicionais exaradas no Brasil (Tabela 1).

Tabela 1: Quantidade de benefícios previdenciários concedidos por via judicial no Brasil por ano ${ }^{3}$

\begin{tabular}{|c|c|c|c|c|c|}
\hline Anos & $\begin{array}{c}\text { concessão de } \\
\text { benefícios } \\
\text { urbanos por via } \\
\text { judicial (A) }\end{array}$ & $\begin{array}{c}\text { benefícios } \\
\text { urbanos } \\
\text { concedidos por } \\
\text { via judicial } \\
\text { (A/C) }(\%)\end{array}$ & $\begin{array}{c}\text { concessão de } \\
\text { benefícios } \\
\text { rurais por via } \\
\text { judicial (B) }\end{array}$ & $\begin{array}{c}\text { benefícios } \\
\text { rurais } \\
\text { concedidos por } \\
\text { via judicial } \\
\text { (B/C) (\%) }\end{array}$ & $\begin{array}{c}\text { total de } \\
\text { benefícios } \\
\text { urbano e rural } \\
\text { concedidos por } \\
\text { via judicial }\end{array}$ \\
\hline 2006 & 6.325 & 10,1 & 56.086 & 89,9 & 62.411 \\
\hline 2007 & 9.011 & 10,8 & 74.324 & 89,2 & 83.335 \\
\hline 208 & 7.603 & 8,2 & 84.140 & 91,8 & 91.743 \\
\hline 2009 & 8.395 & 7,2 & 108.461 & 92,8 & 116.850 \\
\hline 2010 & 8.199 & 7,2 & 104.924 & 92,8 & 113.123 \\
\hline 2011 & 8.950 & 7,3 & 112.662 & 92,7 & 121.612 \\
\hline 2012 & 8.254 & 6,7 & 115.178 & 93,3 & 123.432 \\
\hline 2013 & 8.644 & 6,9 & 116.039 & 93,1 & 124.683 \\
\hline 2014 & 8.313 & 7,3 & 106.184 & 92,1 & 114.497 \\
\hline 2015 & 8.529 & 9,6 & 80.186 & 90,6 & 88.715 \\
\hline 2016 & 9.915 & 11,9 & 72.973 & 88,1 & 82.888 \\
\hline 2017 & 12.189 & 12,8 & 82.866 & 87,2 & 95.055 \\
\hline
\end{tabular}

Fonte: IPEA, Brasil (2018)

A grande judicialização da aposentadoria, além de transferir a titularidade da competência para a outorga do direito, que sai das mãos do Poder Executivo para o Judiciário, provoca um volume de obrigações financeiras oriundas de decisões judiciais que, sem previsão no erário público, não se organizam dentro da estrutura do Estado. Com o passar do

\footnotetext{
${ }^{3}$ No ano de 2014, o STF declarada a constitucionalidade da exigência do prévio requerimento administrativo, para caracterizar o interesse de agir no processo judicial.
} 
tempo, esse fato pode estabelecer desequilíbrio no orçamento próprio e provocar, inclusive, a inviabilidade de determinadas políticas públicas da própria Seguridade Social.

Com o crescimento do conflito na matéria, soma-se que as decisões judiciais, importantes na colaboração das possíveis correções dos erros na entrega do direito, passam a ser concebidas "em massa", devido à falta de estruturação dos órgãos judiciais para operar como operam as agências da previdência social.

O Banco Mundial (2017, p 70) afirma que "o déficit do Regime Geral de Previdência Social (RGPS) no Brasil, urbano e rural, atingiu 2,4\% do Produto Interno Bruto (PIB) em 2016. Sendo a aposentadoria rural responsável por 1,6\% deste déficit” (BANCO MUNDIAL, 2017).

A apresentação da reforma previdenciária de 2019 afirma que os dados do Ministério da Economia apontam que aposentados rurais representam $32 \%$ dos benefícios concedidos no RGPS, mas respondem por uma parte proporcionalmente maior do déficit, qual seja $58 \%$ (cinquenta e oito pontos percentuais).

\section{NATUREZA DA RELAÇÃO JURÍDICA PREVIDENCIÁRIA DO TRABALHADOR RURAL: SEGURO SOCIAL OU ASSISTÊNCIA SOCIAL?}

Inicialmente, a Lei n. 8.212 de 1991 (BRASIL, 1991) previu a contribuição do trabalhador rural para o regime geral, a qual incide sobre a produção agrícola, mas para garantir o direito à aposentadoria por idade, a Lei n. 8.213 de 1991 (BRASIL, 1991) prevê apenas a prova do trabalho rural. Esse fato, aliado a outras benesses, fazem o caráter do benefício, previsto em lei como seguro social, ficar sob suspeita quanto a sua natureza.

A reforma previdenciária de 2019 previu um pagamento de valor mínimo anual pelo trabalhador rural como fonte de custeio e de requisito para participação no sistema, na data da reforma estimado em $\mathrm{R} \$ 600,00$ (seiscentos reais). Porém, tal fato ainda não serve para colocar fim às indagações quanto à natureza da relação jurídica previdenciária do trabalhador rural, tendo em vista ser o valor da contribuição se comparado ao exigido dos demais segurados.

Fica mais evidente a dúvida quanto a natureza do benefício quando o Banco Mundial afirma ser a aposentadoria por idade ao trabalhador rural de cunho social, propondo uma consolidação da assistência social prestada aos brasileiros, que implicaria na reformulação e na integração de todos os benefícios não contributivos de transferência de renda - incluindo 
pensões e aposentadorias de cunho social (benefício assistencial(BPC) e rural) (BANCO MUNDIAL, 2017, 12).

O que se denota das decisões judiciais ordinárias dos Tribunais Regionais Federais brasileiros é que as especificidades da aposentadoria por idade ao trabalhador rural deixaram de ser bismarckianas e ganharam contornos do sistema beveridgiano, colocando o benefício como política pública da assistência social com fins de distribuição de renda, sob a máscara de cobertura de evento velhice própria da previdência social (TAVARES, 2020, p. 189).

Pensar em sentido diferente, tendo em vista os dados do IPEA, seria colocar as decisões judiciais sob suspeita de irresponsabilidade com o orçamento previsto para as coberturas de eventos que são inerentes à previdência social.

No entanto, a assistência social, assim como a saúde, tem diretriz, programas, natureza e, em especial, receita de custeio deferentes daqueles previstos para previdência social, ainda que ambas sejam partes de uma mesma ordem social garantida constitucionalmente, qual seja, a Seguridade Social.

Partindo da seara previdenciária, junto à Administração, todo e qualquer cidadão rural deve, por ele próprio, iniciar à informação de que efetivamente vivenciou o trabalho rural com documentos específicos, em seu nome, cujos fatos poderão ser corroborados por informações orais de pessoas que conhecem os fatos, em processo administrativo.

O Decreto 8.048 de 1999 (BRASIL, 1999), que aprovou o Regulamento da Previdência Social, estabelece que além de documentos enumerados, o Instituto Nacional do Seguro Social (INSS) deva exigir do rurícola que cada documento apresentado seja contemporâneo ao fato a ser provado em cada período.

Junto ao Poder Judiciário, basta que a mulher apresente um documento em nome do marido, no qual conste ele como trabalhador rural, para iniciar prova material a ser corroborada por prova testemunhal, e fazer garantia de ser a esposa, por extensão, trabalhadora da terra.

Em contrapartida, decisões judiciais prolatadas pelo STJ (BRASIL, 2019) mostram que basta apenas, por exemplo, a certidão de casamento em qualquer data, na qual conste a profissão do marido como trabalhador rural para iniciar a prova, ficando a convicção dos fatos pela prova testemunhal, a garantir o benefício previdenciário.

Os filtros judiciais para se extrair os fatos são significativamente mais simples. O julgador, como autoridade máxima capaz de extrair a verdade, faz das provas colhidas no 
processo judicial, em que pese normas em sentido contrário, se restringir à prova testemunhal. E esse tipo de prova pode ser bastante sensível (BRASIL, 1994).

Não há como dizer diferente, visto que o próprio STJ, em resposta à ação em recurso repetitivo (BRASIL, 2014), afirmou que "no tocante ao reconhecimento do tempo de serviço rural, a prova material juntada aos autos possui eficácia probatória, tanto para o período anterior quanto para o posterior à data do documento".

O pensamento pela extensão da profissão é proveniente de jurisprudência do extinto Tribunal Federal de Recurso (BRASIL, 1994) que, sem qualquer contextualização, vem sendo utilizada para fundamentar atuais decisões judiciais. Mas a Administração Pública não referenda esse pensamento, tendo em vista que há diversos fatos sociológicos a serem repensados.

Os primeiros julgados nessa seara, que culminaram na jurisprudência, se deram em vista de o casal morar em propriedades rurais como posseiros, colonos, camaradas, caseiros, arrendatários, etc. A inteligência perpetrada pela jurisprudência, vê-se pela história, se deu com o fato de que ambos, morando em zona rural e, ainda que ela cuidasse apenas da casa, não utilizavam das facilidades urbanas, como gás, água encanada, serviço de saneamento e esgoto, gerando para a esposa o trabalho de providenciar lenha como combustível para fogo que cozinha os alimentos, abastecer a casa com água, cuidar de pequenas hortas e criações, e coisas do gênero. Havia, pode-se dizer, o trabalho rural na síntese do regime de economia familiar.

As decisões judiciais não analisam o fato de o casal residir em centro urbano. Nesses casos, não há evidências de que a mulher acompanha o marido nas lidas do trabalho campesino. Como também não dizem se o entendimento se traduz ou não em isonomia de tratamento em face das demais seguradas urbanas, se não se permite a extensão da profissão do marido trabalhador urbano, quando são elas hipossuficientes financeiro e culturalmente (TAVARES, 2020, P. 187).

A generalização da extensão da profissão do marido rural à esposa, torna ainda mais frágil a natureza de seguro social deste benefício, além de fomentar a grande corrida ao Poder Judiciário.

Antes da declaração de inconstitucionalidade proferida em agosto de 2014 nos autos do recurso extraordinário $n^{\circ} 631240$, com repercussão geral reconhecida, em que o Supremo Tribunal Federal (BRASIL, 2014) declarou ser necessário o prévio requerimento 
administrativo, os pedidos administrativos de aposentadoria por idade rural eram menores quando comparados ao número de ações judiciais nesse mesmo sentido.

\section{AMPLIAÇÃO DO DIREITO SEM DISCUTIR O DIREITO.}

Assentado em efetivar direitos sob a batuta assistencial, a função do judiciário federal ordinário resumiu-se a fazer a análise da presença dos requisitos do benefício, sem fazer ilações verticais sobre o direito, as bases, as diretrizes e os fundamentos que o temaproblema requer. E creditou ao início de prova material, como sendo aquele que o julgador entender como correta, a ser corroborada pela a fala de pessoas que dizem conhecer dos fatos, para se fazer a declaração do direito à aposentação por idade ao trabalhador rural.

Tal atividade exercida em jurisdição está em condição assemelhada àquela exercida por quem a lei entregou a administração do benefício previdenciário, o INSS.

O resultado do processo judicial se satisfaz com a simples análise técnica. A diferenciação em relação ao resultado do processo administrativo se dá pelo entendimento quanto aos documentos que podem ser vistos como início de prova material, à data e à origem desses documentos. Ainda, diferente do que ocorre no processo administrativo, no judicial não é necessário especificar precisamente os lugares trabalhados, os possíveis contratantes do trabalho rural quando não realizado na própria terra ou na terra arrendada, os períodos trabalhados e outros pontos a darem contornos à vida de trabalho campesino por quinze anos (TAVARES, 2020, P. 187).

As decisões judiciais não levaram em consideração os trabalhos realizados em devido processo legal administrativo de pedido de aposentadoria por idade rural, que demandariam afirmar dos possíveis vícios do ato administrativo final.

Nesse sentido, sem discutir o direito, não se abre a possibilidade de melhor análise do tema-problema em esferas especiais junto aos tribunais superiores, eis que os pedidos especiais ou extraordinários se esbarram no enunciado $n^{\circ}$ 07, da súmula do $\mathrm{STJ}$, que proíbe a reanálise de provas. O trabalho ordinário da jurisdição se torna técnico, se afastando das ciências jurídicas.

A jurisdição exercida no cenário brasileiro facilita entregar o benefício do seguro previdenciário a quem não tem direito e negá-lo a quem tem direito, no mesmo patamar dos erros da Administração. 
Nos pedidos de aposentação em processos administrativos, as decisões se fundamentam na legalidade posta em relação ao fato; e no processo judicial, a visão principiológica leva o caráter assistencial a se sobrepor, distanciando o benefício ainda mais do modelo de seguro criado por Bismarck.

A atual análise do direito de o trabalhador rural se aposentar, em processo com sentido único de instrumento na esfera jurídica, como se dá no processo administrativo, adotase exclusivamente o sistema técnico de verificação da presença dos requisitos necessários ao benefício. A singularidade da atividade fortalece a relação de direito público como dogmático, cartesiano que, não preocupada com a validação da relação jurídica, leva o direito previdenciário a fazer descompasso com o orçamento da seguridade social.

O IPEA (2018, p. 16) revela tutelas jurisdicionais "massificadas" para resolver interesse premente e inter partes, sendo elas pensadas apenas na forma binária para a solução do conflito. E no direito público material, o direito previdenciário pode ser um caso típico da indisciplina, fazendo entregar direito a quem não o tem. Visto que em uma visão mecanicista, fica-se com a ideia do discurso sem a visão da Direito. E sem a visão do Direito para iluminar o discurso, o direito pode se tornar 'indisciplinado' pela falta de visão da unidade do sistema que a ele envolve.

A verificação do direito público material unicamente por meio de um viés tecnicista da comprovação fática em caráter subjetivo pelo Judiciário, como é aplicada a fatos no âmbito do direito privado, pode ter como consequência a desordem, o descompromisso, o descomprometimento com as demais políticas públicas e programas sociais, o enfraquecimento dos saberes sociais, das políticas futuras e do desenvolvimento democrático do país.

\section{CONCLUSÃO.}

O direito de o cidadão rural se aposentar por idade está inserido como uma relação jurídica previdenciária, em caráter de seguro, sendo regulado por Lei que prevê e organiza os benefícios previdenciários. Porém, as decisões judiciais propõem que o benefício tenha características de assistencial, diferentemente do que pensa a Administração Pública.

Com o crescente número de pedidos de tutela jurisdicional e o necessário respeito ao princípio da razoável duração do processo, massificam-se as respostas ao processo 
administrativo e judicial. Fomentado pela forma de olhar o benefício, o direito público material tem se construído com a aplicação imediata, técnica e simplista, fazendo perder de vista as necessidades mediatas sociais, tanto no sentido de coletivo, como no sentido individual.

As decisões judiciais observam apenas o contexto assistencial dos interessados em se aposentar por idade na condição de rural, sem adentrar no mérito do Direito, em que a aplicação do fato individual é mais importante que a ciência.

Os atores que se encarregam de analisar o direito da relação jurídica entre o trabalhador rural e a aposentadoria, seja na seara administrativa, seja judicial, precisam apontar os saberes que envolvem a especialidade que a matéria requer, bem como o orçamento e os destinatários do direito, de forma ampla e legítima. Isso não apenas para fundamentar a entrega de verbas públicas, mas também para que se atenda esléticamente a função da seguridade social, fazendo alcançar seus reais fins, seus objetivos gerais e especiais.

Somente observando a complexidade que envolve o direito público advindo de uma política pública, as informações sociais imediatas e mediatas, e uma análise mais profunda do direito que envolve o tema-problema, é que a decisão judicial irá alcançar não só a natureza da relação jurídica a que a Seguridade Social se propõe para a aposentadoria por idade ao trabalhador rural, mas também o referendo da Administração pública no mesmo sentido do julgado.

É preciso definir a natureza jurídica da relação do trabalhador rural com a aposentadoria por idade, criando-se possibilidade para que a Autarquia Previdenciária Federal reassuma o papel que lhe é instituído por Lei, tirando das mãos do Poder Judiciário a realização da tarefa.

\section{REFERÊNCIAS}

ARAGONÉS VIANA, João Ernesto. Curso de direito previdenciário. $7^{\mathrm{a}}$ ed. São Paulo: LTr, 2014.

BANCO MUNDIAL. Um ajuste Justo - uma análise de eficiência e equidade nos gastos públicos do Brasil, volume 1, Síntese. 2017. Disponível em:

http://documents.worldbank.org/curated/en/884871511196609355/Volume-I-s\%C3\%ADntese acesso em 08 ago 2020.

BARBOSA, Rômulo Soares. Direitos Sociais dos trabalhadores rurais no Brasil: A previdência social em questão, in XII Congresso Brasileiro de Sociologia, 2005, Belo 
Horizonte: Sociedade Brasileira de Sociologia, Anais GT11. Disponível em http://www.sbsociologia.com.br/portal/index.php?option=com_docman\&task=doc_download \&gid=497\&Itemid=171, acesso em 03 ago 2020.

BERWANGER, Jane Lucia Wilhelm. Previdência Rural - inclusão social, $1^{\circ}$ ed, Curitiba: Juruá, 2007.

BERWANGER, Jane Lucia Wilhelm. Conceito de Segurado Especial à Luz da Lei 11.718/08. In: Previdência nos 60 anos da Declaração de direitos humanos e nos 20 da Constituição brasileira. Curitiba: Juruá, 2008.

BRASIL. Constituição (1988). Constituição da República Federativa do Brasil. 56a .ed. São Paulo: Saraiva, 2020.

BRASIL, Lei n. 8.213, de 24 de julho de 1991 e suas alterações. Dispõe sobre os Planos de Benefícios da Previdência Social e dá outras providências. Diário Oficial da União, 14 ago. 1998. Disponível em www.planalto.gov.br/ccivil_03/leis/18213cons.htm. Acesso em 03 ago 2020.

BRASIL, Lei n ${ }^{\circ}$ 8.212, de 24 de julho de 1991. Dispõe sobre a organização da Seguridade Social, institui Plano de Custeio, e dá outras providências. Diário Oficial, Brasília, v. 129, n. 142, p. 14801. 25 jul. 1991. Diário Oficial. Disponível em:

www.planalto.gov.br/ccivil_03/leis/18212cons.htm. Acesso em 10 ago 2020.

Brasil, Superior Tribunal de Justiça. Agravo em RE no 1.412.317. Min. Francisco Falcão. 2019. Diário Oficial de Justiça. Brasília, 08 mai 2019. Disponível em https://processo.stj.jus.br/processo/revista/documento/mediado/?componente=MON\&sequenc

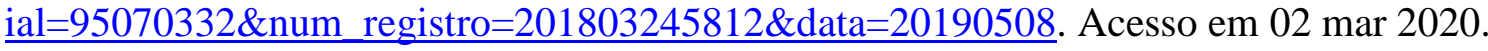

BRASIL, Superior Tribunal de Justiça. Previdenciário, aposentadoria por idade, trabalhador rural, exigências legais. Embargos de Divergência no Resp n. 41.110-4. Min. José Dantas. Brasília: Diário Oficial de Justiça. Brasília, 20 fev 1995. Disponível em:

https://ww2.stj.jus.br/processo/ita/documento/mediado/?num_registro=199400124112\&dt_pu blicacao=20-02-1995\&cod_tipo_documento=1\&formato=undefined . Acesso em $02 \mathrm{mar}$ 2020.

BRASIL, Superior Tribunal de Justiça. Previdenciário. Aposentadoria por idade. Rurícola. Certidão de casamento. Erro de fato. Solução pro misero. Ação Rescisória n. 919. Min. Hamilton Carvalhido. Brasília: Diário de Justiça. Brasília, 05 mar 2007. Disponível em: https://ww2.stj.jus.br/processo/revista/documento/mediado/?componente=ATC\&sequencial= $2465444 \&$ num_registro $=199900309596 \&$ data $=20070305 \&$ tipo $=5 \&$ formato $=$ PDF. . Acesso em 02 mar 2020.

BRASIL, Superior Tribunal de Justiça. Previdenciário. Recurso especial. Enquadramento do trabalhador bóia-fria. Equiparação ao segurado especial. Art. 11, VII, da lei 8.213, 1991. Desnecessidade de recolhimento de contribuições. REsp 1762211, Min. Napoleão Nunes Maia Filho, Brasília: DJe 27 nov 2018. Disponível em: https://processo.stj.jus.br/processo/revista/documento/mediado/?componente=ATC\&sequenci $\underline{\mathrm{al}=89512207 \& \text { num registro }=201802181045 \& \text { data }=20181207 \& \text { tipo }=51 \& \text { formato }=\text { PDF. }}$. Acesso em 10 abr 2020.

Brasil, Superior Tribunal de Justiça. Previdenciário. Recurso especial representativo da controvérsia. Aposentadoria por tempo de serviço. Art. 55, § $3^{\circ}$, da lei 8.213/91. Tempo de 
serviço rural. Reconhecimento a partir do documento mais antigo. Desnecessidade. Resp 1.348.633. Ministro Arnaldo Esteves Lima. Brasília: Diário Oficial da Justiça. Brasília 05 dez 2014. Disponível em:

https://processo.stj.jus.br/processo/revista/documento/mediado/?componente=ITA\&sequencia $\underline{1=1242765 \& \text { num registro }=201202142030 \& \text { data }=20141205 \& \text { formato }=P D F}$. Acesso em 03 mar 2020 .

Brasil, Superior Tribunal de Justiça. Previdenciário. Trabalhador Rural. Aposentadoria por Idade. Requisito. Resp 45568. Min. Jesus Costa Lima. Brasília: Diário Oficial da Justiça. Brasília 30 mai 1994. Disponível em: https://processo.stj.jus.br/processo/ita/documento/mediado/?num_registro=199400077246\&dt _publicacao=30-05-1994\&cod_tipo_documento=3\&formato=PDF acesso em 02 mar 2020.

CÂMARA, Karina. A aposentadoria por idade rural e seu caráter assistencial. Revista de Estudos Jurídicos, v. 15, n. 22, p. 173-190. Franca: UNESP, 2011.

CARVALHO FILHO, José dos Santos. Manual de Direito Administrativo. Rio de Janeiro, $33^{\circ}$ ed. São Paulo: Atlas, 2019.

COUTO E SILVA, Almiro do. Princípios da legalidade da administração pública e da segurança jurídica no Estado de Direito contemporâneo. Revista de Direito Público, Rio de Janeiro, n. 84, out./dez., 1987.

DELGADO, Guilherme Costa. Universalização de Direitos Sociais Mínimos no Brasil: o caso da previdência rural nos anos 90. Brasília: IPEA, 2000.

DURANT, Paul. La Politica Contemporânea da Seguridad Social. Madri: Ed. Ministério do Trabajo e Seguridad Social, 1991.

GEPP, Jonh Neville. A pensão por morte no regime geral da previdência social e o ordenamento jurídico comparado. Dissertação (Mestrado em Direito), Universidade de São Paulo (USP), 2009.

IBRAIM, Fábio Zambitte - Curso de Direito Previdenciário - 25 edição, Niteroi: Impetus, 2020.

MARANHÃO, Rebecca Lima Albuquerque; VIEIRA FILHO, José Eustáquio Ribeiro, Previdenciária Rural no Brasil, Instituto de Pesquisa Econômica Aplicada - IPEA, 2018. Disponível em: http://repositorio.ipea.gov.br/bitstream/11058/8690/1/td_2404.pdf, acesso em 20 jul 2020.

MARTINEZ, Wladimir Novaes. Curso de Direito Previdenciário. $7^{\mathrm{a}}$ ed, São Paulo: LTr, 2017.

MARTINEZ, Wladimir Novaes. Princípios De Direito Previdenciário. $6^{\mathrm{a}}$ ed, São Paulo: LTr, 2015.

MARTINS, Nádia Bevilaqua, Da Obsolescência Disjuntiva Dialética para a Construção Conjuntiva Exlética, Brisbane, 2001.

NICOLESCU, Basarab. Manifesto da Transdisciplinaridade. São Paulo: Trion, 1999.

SANTOS, Wanderley, G. Cidadania e Justiça. Rio de Janeiro: Editora Campus, 1979.

SCHWARZER, Helmut. Paradigmas de previdência social rural: um panorama da experiência internacional. Brasília/DF: Planejamento e Política Pública-IPEA, n. 23, 2001. 
TAVARES, Marco Arlindo. Dinâmica na formação de decisão nos processos judiciais que garantem a aposentadoria por idade rural. Uma análise documental. I Encontro Virtual do CONPEDI: Constituição, cidade e crises. Encontro Virtual, Anais, 2020.

VALADARES, Alexandre Arbex Valadares; GALIZA, Marcelo Galiza. PREVIDÊNCIA RURAL: Contextualizando o debate em torno do financiamento de regras de acesso. IPEA, Brasília, maio, 2016.

VENTURI Augusto: I fondamienti scientifici della sicurezza sociale. Trad. Gregorio Tudela Cambronero. In: Los fundamentos científicos de la seguridad social. Madrid: Centro de Publicaciones, Ministerio del Trabajo e Seguridad Social, 1994.

VIANNA, Luiz Werneck. [1976] Liberalismo e Sindicato no Brasil. 4a ed. Belo Horizonte: Editora UFMG, 1999. 